GLOBAL DEVELOPMENT AND ENVIRONMENT INSTITUTE

WORKINg PAPER No. 05-04

\title{
Rationality and Humanity: A View from Feminist Economics
}

\author{
Julie A. Nelson
}

May 2005

Tufts University

Medford MA 02155, USA

http://ase.tufts.edu/gdae 


\title{
Rationality and Humanity: A View from Feminist Economics
}

\author{
Julie A. Nelson ${ }^{1}$
}

\begin{abstract}
Does Rational Choice Theory (RCT) have something important to contribute to the humanities? Jon Elster and others answer affirmatively, arguing that RCT is a powerful tool that will lend clarity and rigor to work in the humanities just as it (presumably) has in economics. This essay examines the disciplinary values according to which the application of RCT in economics has been judged a "success," and suggests that this value system does not deserve general approbation. Richness and realism must be retained as important values alongside precision and elegance, if anti-scientific dogmatism and absurd conclusions are to be avoided.
\end{abstract}

\footnotetext{
${ }^{1}$ This paper was prepared for the conference "Rational Choice Theory and the Humanities," sponsored by the Program in Modern Thought and Literature at Stanford University, April 29-30, 2005.
} 


\section{Introduction}

Does Rational Choice Theory (RCT) have something important to contribute to the humanities? Usually the arguments for answering “yes” to this question go something like the following: The application of RCT has proved to be a powerful tool in economics and the social sciences, leading to clear and rigorous insights unattainable from less precise methods. Therefore, by also harnessing this power, the disciplines in the humanities could advance towards becoming more elegant, rational, and forceful in their explorations of human behavior.

As an economist, I'd like to address this argument on its home ground. Has the use of RCT advanced economics in good and useful ways? More precisely, what are the disciplinary values adopted in economics according to which the application of RCT has been judged a "success"? Is this system of values one we want to continue to endorse even in economics, not to mention more generally?

\section{Defining RCT}

First, to clarify, let me define the territory of RCT. As I understand the situation in the humanities, RCT is understood in terms of a set of principles such as those outlined by Jon Elster:

any given piece of human behavior may be seen as the end result of two successive filtering devices. The first is defined by the set of structural constraints which cuts down the set of abstractly possible courses of action and reduces it to the vastly smaller subset of feasible actions. The second filtering process is the mechanism that singles out which member of the feasible set shall be realized. Rational-choice theories assert that this mechanism is the deliberate and intentional choice for the purpose of maximizing some objective function.

$$
\text { (Elster, 2000a, 200-1) }
$$

This does distill the essence of the theory, though in my training as an economist we were exposed to this theory from a somewhat different angle.

Economists tend to conceptualize RCT in symbolic, mathematical terms of timeless, static choice, rather than in terms of a verbal story (however simple) that subtlety implies that events happen "successively." Economists would say that individuals have well-defined preferences over a choice set. Preferences are assumed to be characterized by the logical relations of reflexivity, completeness, transitivity, and independence of irrelevant alternatives. Because of these logical restrictions, preferences can be represented by a single-valued function. To choose rationally is to solve for the most preferred element, that is, the element in the choice set that maximizes the value of the objective function subject to constraints. Economists usually also find it helpful to assume nonsatiation and free disposal, and that the objective function has the properties of continuity, strong monotonicity, and convexity, since then calculus can easily be 
applied. What economists mean by "precision" and "elegance" in analysis is not simply that an analysis starts with the general concept verbally outlined by Elster, but that the analysis includes a precise application of symbolic logic and an intensive manipulation of mathematics. Core graduate courses in most economics departments, for example, consist largely of the study of theorems and proofs, and the working of mathematical problem sets.

So I have found it rather interesting to observe RCT being used in the humanities in what would appear to an economist as a relatively vague and verbal sense. What passes for RCT in the humanities, while it might be considered "interesting reading" by mainstream economists, would not be considered rational choice theorizing. As a group, economists tend to only see only exercises that include theorems or equations as theorizing. However, for the purposes of this paper, I will accept Elster's definition of RCT as the one relevant to the topic at hand.

\section{Descriptive or Normative?}

The first question we must address is whether RCT is meant to be descriptive or normative. Does it aspire to explain how humans behave, or does it set up standards concerning how humans should behave? If it is meant to be explain actual behavior, but it is found to be descriptively inadequate in the light of evidence, then one would think it should be looked at rather skeptically. If more adequate explanations exist, one would think that these should be favored.

While many of my economist colleagues prefer to continue to believe otherwise, nearly everyone interested in this area has by now realized that the preponderance of evidence shows RCT to be terribly inadequate as a general description of human decision-making behavior. Through laboratory and survey studies, Amos Tversky, Daniel Kahneman, and Richard H. Thaler have famously showed how factors such as emotions, the use of heuristics, psychological framing, and poor handling of low probabilities make people behave quite differently from the logic-processing machines we are assumed to be in RCT (see summary in Kahneman 2003). Neuroscientists trace our behaviors to their source in our "three brains"-reptilian, old mammalian, and neocortex — only the last of which has any relation to analytical reasoning. Many economists have noted that most real-world decision making involves many factors assumed away in RCT, such as costs of information, incomplete preferences, and true uncertainty about the future. Alternative theories, such as Herbert Simon's theory of satisficing (1955), as well as theories involving heuristics, melioration, habituation, social norms, prospect theory, and pattern recognition offer much more empirically satisfying explanations of how the human animal tends to perceive, process, and act. Our desire to make our perceptions and actions fit together "rationally" has too often been shown in actual studies to be a process of rationalization, if not outright confabulation.

We could debate these very interesting studies all day long, but for the sake of my argument here I will assume that the case against RCT as a generally accurate 
explanation of human behavior has been soundly disproved. Jon Elster, for example, in his 1990 essay "When Rationality Fails," acknowledges that, in light of the abovementioned evidence, we must conclude that "indeterminacy and irrationality are widespread" (41) and that some of the alternative theories are more realistic (42).

\section{Academic Values}

In spite of the failure of RCT to provide realistic explanations of behavior, Elster in the same 1990 essay nevertheless asserts that RCT should enjoy "explanatory" as well as "normative privilege" $(1990,41)$ over competing theories of behavior. How can this be?

To study this assertion, we have to move from questions about the principles of human behavior themselves to the question of how a group of scholars can come to privilege one explanatory approach over another.

Economist Joseph Perksy, for example, has spelled out a rationale that is very common among RC theorists. A theory of behavior must be "must be parsimonious" in its assumptions, he writes, including only a "manageable" set of human motivations, lest the ability of the model to yield "tightly reasoned generalizations" be lost (1995, p. 230). Elster explains the reasons for his own a priori privileging of the propositions of rational choice along the same lines. RCT should be honored with explanatory privilege over competing theories of behavior, Elster claims, because of its "parsimony," "robustness," "simplicity," "generality," and "power" (1990, 42-47). ${ }^{2}$ The epistemological ideal of parsimony is derived from the principle of Ockham's Razor--that is, that one should not make any more assumptions than the minimum needed. Note that in this view, parsimony, simplicity, precision, generality, and tight reasoning are given high—and, in fact, exclusive - value. What we have here is a statement about a value system: among the many possibly epistemological criteria that might be considered, only these goals are to be considered worthy of pursuit.

Just as the epistemological ideals reflect a certain set of values, so do the substantive assumptions RCT makes about human nature. The assumption of rationality should be normatively privileged, says Elster, because "we want to be rational" (1990, 41). Along with rationality, the theory takes as an unstated assumption that autonomous, self-interested agents have already been unambiguously identified as the locus of decision-making activity. Autonomy and self-interest have strong positive, if often unconscious, valence among adherents of RCT.

While RCT is often presented as somehow neutral and "value-free," the idea that

\footnotetext{
${ }^{2}$ Elster has, of course, also decried "hyperrationality" or the two-tight imposition of the criteria of rationality (e.g., 2000b, 695). Because, however, he both decries "hyperrationality" $(1990,26,39)$ and asserts "normative" and "explanatory privilege" for RCT within a single work (1990), I find it difficult to locate a consistent viewpoint in his work. In any case, it is the "privileging" view such as described in Elster (1990) and Perksy (1995) that is the subject of this paper, not the work of any particular author.
} 
RCT provides a superior model of human behavior is firmly based in valuing a very particular subset of possible epistemological and substantive ideals. This is where the problem with RCT lies.

Note that the list of RCT-favored epistemological ideals leaves out many properties that can very arguably also be considered to be essential characteristics of a good theory. Other worthy goals include realism, accuracy, richness, comprehensiveness, an appropriate level of complexity, applicability, and usefulness is addressing some issue of pressing concern. As I will demonstrate below in the case of economics, a one-sided adherence to the ideals elevated in RCT can lead to explanations that score abysmally low on these other criteria. Simplicity, for example, can be taken much too far, leading to conclusions that are so unrealistic as to be totally ridiculousand sometimes positively damaging if taken as a guide for action. If one is conscious of only a limited range of virtues, one is easy prey for a considerable number of vices.

The substantive assumption that human behavior is only a matter of mental decision-making by rational, autonomous and self-interested agents is similarly narrow. Elster, for example, seeks to justify the rationality norm by claiming that "Communication and discussion rest on the tacit premise that each interlocutor believes in the rationality of the others" $(1990,41)$. Others may legitimately disagree, pointing to the role of empathy in creating grounds for communication, or simply to the fact that communication can arise because a person needs something from another. Emotion, bodily needs, human dependencies and interdependencies, social connection, ethical sensibilities, and other-regarding interests, as well as the biological and social evolution of people in real historical time, have been clearly shown to be important factors in explaining human behavior. They are excluded from serious consideration by adherents of RCT not on any empirical basis, but because rationality is what "we want"--and because their inclusion might interfere with the achievement of "parsimony" and "tightly reasoned" conclusions.

Because RC theorists value only a particular subset of worthy scholarly ideals, RCT adherents have had to resort to rhetorical tricks and fall back on cultural stereotypes to try to prevent serious consideration of the ideals they neglect. Someone might, for example, advocate an alternative theory on the basis of its accuracy, realism, or helpfulness in solving a specific real-world problem. If, however, this alternative theory does not fully measure up to RCT standards of precision, parsimony, and generality, RCT adherents will denigrate the upstart as "soft," "vague," "messy" or "insufficiently general." They may even criticize an advocate of such a theory for being too concerned with real-world problems and hence insufficiently "objective.” Similarly, an alternative model of human identity that might seriously consider factors such as emotions or bodily needs can be stigmatized by being labeled as being applicable only to a more "primitive" or "animal" aspect of behavior, presumably overridden in modern humans by our superior rational capacities. It is by these tricks-elevating one set of academic and philosophical ideals while denigrating additional and alternative valuable goals - that the "privileging” of RCT makes advances. 
But enough of generalities--let us turn to the history of economics to see how it was that RCT gained its prominence there, and what the consequences have been.

\section{The Roots of RCT in Economics}

The word "economics" literally, by its Latin roots, means "management of the household." At the time of the birth of modern economics, the focus of economics was the creation and distribution of "wealth." One useful definition of economics is that it is about "provisioning," or how societies organize to provide for the sustaining and flourishing of life. Certainly the person-on-the-street today usually thinks of “economics” as being about jobs, money, and making ends meet.

Yet for many, contemporary economics has come to be identified with working out the implications of RCT rather than with anything practical about living in this world. Content has taken a back seat to methodology. For starting this process, we have John Stuart Mill to thank.

In his 1844 essay “On the Definition of Political Economy,” Mill attempted to carefully distinguish economics from the physical sciences and technology, from ethics, and from a more general study of social behavior. Political Economy is distinguished from physical science, he wrote, because it is about "phenomena of mind" $(1844,29$, emphasis in original) or "mental laws" (29) rather than about physical laws. Among the mental sciences, it is further distinguished by the particular "part of man's [sic] nature” (36) with which it deals. Conscience, duty, and other feelings relevant to a person's dealings with other individuals were consigned by Mill to the realm of ethics (34). Principles of human nature that have to do with life in society were consigned by Mill to the realm of "speculative politics" (which he also called "social economy") (35). With issues concerning physical bodies, ethics, and social interactions split off and assigned to other disciplines, Political Economy would deal with what was left. It should, Mill wrote, deal with "man $[\mathrm{sic}]$... solely as a being who desires to possess wealth, and who is capable of judging of the comparative efficacy of means for obtaining that end" (38). Here is the nub of RCT, in the original description of "economic man."

Mill believed that he had to separate out a very thin slice of human nature for analysis by each of the various fields because this was required by the nature of science. Significantly, his model for science was geometry. Political Economy, Mill thought, could only proceed as a "pure" and "abstract" science, resulting in general truths and timeless laws, if it posited a minimal set of starting principles. Political Economy and geometry, he claimed, both "must necessarily reason...from assumptions, not from facts" $(1844,46)$. Political Economy presupposes “an arbitrary definition of man, as a being who invariably does that by which he may obtain the greatest amount of necessaries, conveniences, and luxuries, with the smallest quantity of labor" for the same reason that "[g]eometry presupposes an arbitrary definition of a line, 'that which has length but not

\footnotetext{
${ }^{3}$ The label "economic man” was not applied until somewhat later.
} 
breadth'” (46). He chose geometry as his model, rather than the physical sciences, because he believed that "mental" phenomena (unlike physical phenomena) were not amenable to controlled experiments. Having no way, then (he thought), to systematically study cause and effect by experimental methods and induction, Political Economy would need to start with assumptions and derive truths by deduction. The assumptions about "man's nature” could come, he said, by introspection--“knowledge every one can principally collect within himself [sic].”

Mill, to his credit, in principle left his premises open (64). He argued that no political economist would ever be "so absurd as to suppose that mankind" is really described by only the parts of human nature selected for study in Political Economy (38). He explicitly presented his assumptions of self-interest and rationality as arbitrary and partial, chosen not for comprehensiveness but for the goal of creating conclusions by logical deduction. In any application, he said, Political Economy would need to be complemented by the insights of other sciences that had focused on other parts of human nature and other circumstances (58), and also by practical knowledge of specific experiences (68).

Alas, however, what remained and flourished in later economic thought was not Mill's modesty concerning the ad hoc premises and limited applicability of the geometrylike discipline he proposed, but rather his idea that Political Economy must become a axiomatic-deductive enterprise in order to be "scientific." This approach received a big boost in the late $19^{\text {th }}$ century when neoclassical economists (including Edgeworth, Jevons, Walras and Pareto) found that they could mathematically formalize Mill's idea of the "desire for the greatest amount" of wealth in terms of maximization of profit and utility functions. In the 1930's, economist Lionel Robbins offered his precedent-setting definition of economics as the science of choice-making in the face of unlimited wants and scarce resources. Through such an historical process, the original broader meaning of economics in terms of processes of wealth creation and distribution increasingly gave way to the currently dominant, narrow emphasis on the calculus of rational choice.

\section{How RCT Has Done Economics Wrong}

Because geometry, rather than a broader ideal of systematic investigation, has been taken as the model for economic "science,” RCT has become economic's Procrustean bed. Only those aspects of a problem that can be analyzed through application of an axiomatic-deductive methodology, using key assumptions of rational self-interest, have been allowed. Issues that any normal person would classify as "economic" in subject have increasingly become warped as they have been subjected to the strictures of tightly-enforced RC theorizing. The results of applying RCT exclusively have often been--as Mill himself predicted--absurd. Here are a few of my favorite examples.

One of the substantive issues of economics is the problem of unemployment. The inability of an economy to create jobs for everyone who wants to work and use their 
skills creates insecurity and hardship for many. Now let's give unemployment an RCT twist. Robert Lucas, leader of the influential Rational Expectations school of macroeconomics in the 1980s, has argued that RCT provides the "only 'engine of truth' we have in economics" $(1987,108)$. He therefore has said that the problem for economists is to explain why people choose to be unemployed-why they "prefer" this use of their time "to other available activities" $(1987,54)$. The answer given by Real Business Cycle theorists of the same period was that the unemployed are "intertemporally substituting leisure"- that is, taking a vacation.

Another substantive problem for economists is comparing the adequacy of income levels across households of different sizes and types. Even the crudest of poverty lines or distribution studies has to make some assumption about how much pressure additional people put on a household budget. Welfare policies, often motivated by a special concern for the physical well-being of children (e.g., “do they have enough to eat?”), require such information. Early studies often formulated the question as measurement of the "cost of children.” But now let's force this to fit RCT, in which all agents are autonomous, rational, and self-interested, and in which only factors related to mental cogitations - not physical need-are allowed to enter. Following the strictures of RCT theory, the notion of household material well-being was transformed into the notion that adult decisionmakers "maximize utility." If we also assume that adult decision-makers choose the number of children to have, then it follows that the psychic benefit parents receive from having children must at least make up for their "cost." ${ }^{4}$ Arguing along these lines, economists M. Luisa Ferreira, Reuben C. Buse, and Jan-Paul Chavas (1999) have argued that anti-poverty programs are therefore problematic because they "overcompensate" parents for the cost of children. Note that the children themselves and their physical wellbeing have totally disappeared from this picture. In this way the problem of child poverty - the physical suffering and stunted development of those in our society who are most manifestly not autonomous - is erased by the application of “rigorous” RCT economics.

One might think that actual economic developments over time are closely enmeshed with social and political historical events, in all their multiplicity and complexity. RCT economists, however, find this idea uncomfortable. They would like to think of their model, based on RCT and markets, as a closed system which has no need to draw exogenous ("outside the model”) explanations from other disciplines or experience. As a result, they are always looking to find ways to explain historical events as the outcomes of a minimal number of endogenous ("inside the model") economic variables or “economic fundamentals.” Economists Robert Barsky and Lutz Kilian (2004), for example, have recently published an article designed to put such minds at ease concerning oil prices and macroeconomics. An historian, or a normal sane person, might think, for example, that the oil price shock and macroeconomic fluctuations of 1973-74 had something to do with a political event, namely the supply embargo initiated by a number of Arab countries in response to Western support for Israel in the Yom Kippur War. Barksy and Kilian, however, argue that changes in oil prices can be explained by macroeconomic fundamentals $(2004,116)$. The spike in the price of oil in 1973, they

\footnotetext{
${ }^{4}$ This history is traced in Nelson (1996, Chapter 6).
} 
claim, had little to do with politics, but rather is best explained as "a delayed adjustment of the price of oil to a preceding demand boom” (130). The formation of OPEC, they imply, was a function of interest rates (126). Apparently, we do better economics the more we try to explain away the importance of actual historical and political events.

A similar dogged allegiance to a narrow set of epistemological ideals, methodological tools, and substantive assumptions characterizes the field of Endogenous Growth Theory (EGT). EGT pursues explanations of technological innovation and growth in Gross Domestic Product, that, no matter how tortured the logic, lead back to a source in economic fundamentals. As Robert Lucas has also been among the key players in this area, you can guess that it features RCT. And the word "endogenous" is a signal that it attempts to close the model off from novel historical developments. Mark Blaug, one of the rare economists who take history and methodology seriously, has posed the critical question, “[W]hy is there so much fuss about EGT?” He answers his own question by pointing out that "it features a brand of theorizing that is at times analytically elegant and at all times analytically demanding...The modeling itself is frequently ingenious but it simply reeks of ad hoc assumptions that sound plausible and may even be true, but we are given no hints of how to discover whether they are in fact true” (209). Any evidence to the contrary (such as of real novelty of invention) is set aside. And, in line with the vast majority of economic theorizing about growth, the ecological implications of a ceaseless expansion of production are totally ignored.

If these were isolated examples, rapidly discredited by more responsible economists, there perhaps would not be so much to worry about. But Robert Lucas was rewarded for this work with the Nobel Prize in Economic Sciences. Welfare policy increasingly adopts RCT-influenced economics by spotlighting adult behavior and incentive effects, while considerations of child welfare go by the wayside. The article on oil prices passed peer review and was published in one of the official journals of the American Economic Association. Growth theory, and growth economics in general, remains doggedly blind to the negative ecological impact of our obsessive drive to expand marketed economic activity. Absurdity and irresponsibility--as long as they come along with parsimony and a strict allegiance to the favored assumptions of RCT--are rewarded. Richness, realism, and usefulness are punished. ${ }^{5}$

I earlier posed the question, "Has the use of RCT advanced economics in good and useful ways?” The answer is "no.” The sort of "clarity," "strength,” "power," and "rigor" that RCT has lent to economics is the "clarity" that comes from not feeling any need to entertain alternative theories, the "strength" that characterizes its adherents' allegiance to a narrow methodology, the "power" RCT adherents are granted when people accept their ad hoc premises as revealed truth, and a "rigor" mortis in respect to pursuing evidence that might threaten to contradict core assumptions.

\footnotetext{
${ }^{5}$ While there are alternative schools within economics that begin from premises other than RCT (such as Old Institutionalist, Post Keynesian, and social economics), these are considered "non-rigorous" and are very much marginalized.
} 


\section{Gender and Academic Values}

There still remains the question of how such a way of thinking, which pulls us away from a search for valid explanations and towards a complacency with elegant but unfounded ones, gained such a near stranglehold on economics. Feminist theorists and others who have studied the role played by gender in the rise of modern science offer one explanation for which there is considerable historical and psychological evidence (Harding 1986, Keller 1985).

The term "gender" does not refer to biological sex, but to the social constructions that cultures make on the base of sexual dimorphism. Of particular interest for our purposes is what we might call cognitive gender, or the way that our Western minds tend to organize a variety of disparate concepts on the basis of the dualism "male/female." Most people in Euro-American cultures will, for example, think of dogs as somehow masculine and cats as somehow feminine (even though of course both species come in both sexes). Very often this dualistic metaphorical structure is also hierarchical. The term "virile," for example, refers to a masculine trait with a positive connotation, while the term "effeminate" carries negative valence. Masculinity is traditionally associated with strength, and femininity with weakness.

When John Stuart Mill set up geometry as the model for economics, he drew on the Cartesian tradition in the philosophy of knowledge. According to Descartes, the cosmos is split into a res cogitans (a thinking something which has no spatial extension) and a res extensa (a spatial something which has no psychic qualities). The mind is considered to be the active, valuable part with which "rational man" identifies, reigning over the passivity of matter and the body. Descartes believed that there was only one way to gain knowledge: "The long concatenations of simple and easy reasoning which geometricians use in achieving their most difficult demonstrations gave me occasion to imagine that all matters which may enter the human mind were interrelated in the same fashion" (quoted in Davis and Hersh 1986, ix). For Descartes-and later for Mill--the only true knowledge, therefore, was that which could be expressed in the form of geometry-like theorems and proofs.

In characterizing "rational man" by traits of mind, activity, rationality, detachment, and a search for generalities, all the human characteristics not included in this picture were split off-and projected onto women. James Hillman has written, "The specific consciousness we call scientific, Western and modern is the long sharpened tool of the masculine mind that has discarded parts of its own substance, calling it 'Eve,' 'female' and 'inferior'” (quoted in Bordo, 1986, 441). The counterpoint to "rational man," Elizabeth Fee has pointed out, is "woman [who] provides his connection with nature; she is the mediating force between man and nature, a reminder of his childhood, a reminder of the body, and a reminder of sexuality, passion, and human connectedness." $(1983,12)$.

The outcome of such splitting in economics can be summarized by examining core vs. marginalized characteristics of method and assumptions about human nature, as 
in Table 1. The standard mainstream economics approach is thoroughly permeated by an elevation of the characteristics in the left-hand column, and denigration of those in the right. Postmodernists and deconstructionists will understand immediately how modernist economics' claims to universalism, objectivity, etc. are in fact completely dependent on the subordinate side of theses dualisms. But, as a social scientist at heart, I am not content with stopping at deconstruction. ${ }^{6}$ Since, at the end of the day, social science still needs guides for good practice, some way of going beyond these dualism must be found.

Table 1

The Contemporary Definition of Economics

Methods:

rigorous

intuitive

precise

vague

mathematical

verbal

general

elegant

particular

messy

Key Assumptions:

autonomous

dependent

self-interested

other-interested

rational

emotional

makes choices

acts by instinct

has preferences

has needs

Associations:

masculine

feminine

men

women

mind

body

human

animal

cultured

primitive

The point of such a table is not to reify these dualisms, but rather to bring them out from an unconscious level into the light of awareness where they can be examined. By using such a table I in no way mean to endorse the idea that women are "by nature" more emotional or embodied_-or, a la Lawrence Summers' recent comments, less able in mathematics and science. Rather, the point is that these dualisms reflect a cognitive habit that deeply permeates our Western and modern way of thinking, while the dualisms are also imposed, externally and socially, onto differently sexed bodies.

I've explored many of these dualisms elsewhere, but let me offer a new way of thinking about these, and then an application to the value-laden dualisms "precise/vague"

\footnotetext{
${ }^{6}$ I believe that perceiving a thoroughgoing, relativist deconstructionism as the only alternative to modernist itself is an outgrowth of habits of dualistic thinking. Such an approach only admits extremes such as universalism versus fragmentation, or pure givens vs. pure social constructions. Lively, creative, and knowledge building practice, I believe, takes place in the space between such extremes (Nelson, 2001).
} 
and "autonomous/dependent."

These dualism get their power by relying on ingrained habits of "either/or" thinking and a strong implicit belief in the superiority of traits culturally labeled as masculine. After all, who would choose to be "vague" or utterly "dependent"? Vagueness and dependency are hardly ideals that anyone can endorse. But they are not the only alternatives.

\section{Beyond Dualistic Thinking}

The key to getting out of this strait-jacketed thinking is to begin to imagine alternatives that reflect "both/and" thinking. This can be difficult, since our language itself often presents barriers. For example, I earlier mentioned "virile/emasculated" as an example of a hierarchical dualism. We could illustrate this as:

\section{Masculine, Positive \\ virile \\ emasculated \\ Feminine, Negative}

Virile is defined in the dictionary as "manly vigor." Emasculation is the lack thereof. But are all things feminine just degraded forms of masculine characteristics? If you look hard enough in a large dictionary, you can also find the term "muliebrity" defined as "womanliness" or the feminine "correlative of virility." This suggests that alongside and on a par with a masculine, positive characteristic we might also consider there to be a feminine, positive characteristic, which we might illustrate as:

\begin{tabular}{l|l} 
M+ & $\mathrm{F}+$ \\
virility & muliebrity \\
\hline $\mathrm{M}-$ & $\mathrm{F}-$ \\
$?$ & emasculation
\end{tabular}

There is, unfortunately, no term in the English language for a lack of womanly vigor.

Now let's turn to the idea that alternatives to RCT are "soft," "vague," or "messy." Blaug, for example, after criticizing EGT, goes on to argue for more use of "the 
admittedly fuzzy insights of historical case studies...business histories, interviews, expert testimony..."(210, emphasis added). Kahneman writes that economists seem to think that any alternative to the rational-agent model represents “chaos” $(2003,1449)$. While Blaug and Kahneman believe that less precise methods can bring about better science, to RCT enthusiasts any "vagueness" is a sign of weakness.

Precision is, indeed, superior to vagueness, if that is the only dimension being considered. But the achievement of precision requires a certain narrowing of the subject, since purely precise methods, such as mathematics, can only deal with abstract and tightly delineated concepts. All evidence suggests that precise, step-by-step reasoning involves only a subset of the human capacity to reason and to know. Nicolas GeorgescuRoegen, for example, called economist's fascination with precision "arithmomania" (1971). The other main mode of reasoning is what Georgescu-Roegen called "dialectical” thinking, but which others have identified as including the use of pattern recognition, metaphor, and other important cognitive capacities. This latter mode is much better suited to dealing with concepts that can be less precisely delineated, and in fact may overlap with their opposites. A single-minded pursuit of precision leads to overly narrow, thin analysis, since it must abstract from all realism, context, and substance. Attention to realism, context, and substance, on the other hand, lend richness, fullness, and depth to our investigations. This can be illustrated as:

\begin{tabular}{l|l} 
M+ & $\mathrm{F}+$ \\
precise, & rich, \\
elegant & realistic \\
\hline M- & F- \\
unrealistic, & imprecise, \\
thin & vague
\end{tabular}

If precision is all one is aiming for, one is easy prey to the vice of thinness - and, as shown earlier, resulting absurdities. Daniel Kahneman, for example, notes that he often hears criticism from economists about psychology's "failure” to "match the elegance and precision" of the rational-agent model. But, he says "this is just another way of saying that rational models are psychologically unrealistic” (2003, 1449).

Investigation that aims for a high level of precision and elegance without sacrificing richness and realism (or vice versa), on the other hand, avoids the pitfalls of both thinness and vagueness. To put it in terms of the unconscious gender bias, much of the power of RCT over economics has come from a one-sided elevation of masculineassociated ideals - represented in the top left quadrant of the diagram--instead of an balanced respect for good ideals-represented in the top half of the diagram. It is to this 
sexist elevation of only one dimension of criteria for knowledge, and disrespect for the feminine-associated dimension, that the absurdity of many economists' conclusions can be traced.

Let us also examine the dualism “autonomous/dependent.” In much of Western thought, someone who is fully human is pictured as an autonomous individual who can exert his will on the world. Any creature who is not blessed with such autonomy is thought to operate on a lesser level. Historically, children, women, slaves, barbarians, and animals have all at times been included in this latter group. We are thought to operate on a more emotional and instinctual level than "rational man.” We are seen as properly "his" subjects and dependents.

I have elsewhere elaborated further on the gendered aspects of this premise of autonomy:

Thomas Hobbes... wrote, "Let us consider men . . . as if but even now sprung out of the earth, and suddenly, like mushrooms, come to full maturity, without all kind of engagement to each other" ...Homo economicus is the personification of individuality run wild. "Economic man," the "agent" of the prototypical economic model, springs up fully formed, with preferences fully developed, and is fully active and self-contained. He has no childhood or old age; no dependence on anyone; no responsibility for anyone but himself. The environment has no effect on him, but rather is merely the passive material, presented as “constraints,” over which his rationality has play...Homo economicus is the central character in a romance of individuality without connection to nature or to society.

Yet humans simply do not spring out of the earth. Humans are born of women, nurtured and cared for as dependent children, socialized into family and community groups, and are perpetually dependent on nourishment and shelter to sustain our lives. These aspects of human life, whose neglect is often justified by the argument that they are unimportant or intellectually uninteresting or merely "natural," are, not just coincidentally, the areas of life thought of as "women's work.”

(Nelson, 1996, 30-31)

Autonomy is not a fact of human existence, but rather a mythical construct that is coherent with distinctly masculine-biased world views.

Theologian Catherine Keller (1986), has presented an analysis of this contrast between separation and connection that has been a source for both my (1996) and Paula England's (2003) thinking on this topic. In brief, Keller argues that in Western culture individuality has been stressed for men to the point where it takes on the perverse and extreme form of a mythical ability to live without any dependence on others. She calls this the image of the "separative" self. On the other hand, relatedness has been stressed for women, to the point where women have been rewarded for trying to let our own identities dissolve in marriage and family. Keller calls this the "soluble" self. This can be 
pictured as:

\begin{tabular}{r|l} 
M+ & $\mathrm{F}+$ \\
individual & related \\
\hline $\mathrm{M}-$ & $\mathrm{F}-$ \\
separative & soluble
\end{tabular}

While both individuality and relation are part of actual human identity, RCT and related theories treat individuals as isolated or separative. ${ }^{7}$

A similar analysis can be applied to the relation of mind and body: RCT considers the mind as an entity quite removed from the body (separative). This is true whether you think of the body in terms of actual bodily needs (that require provisioning) or as the organic, evolved, emotionally-wired "wet-ware" in our bodies that provides the base for our cognition and actions. A more balanced view would recognize the deep embeddedness of our cognitive processes in our social and physical worlds, while not denying the uniqueness of individual histories and experience.

Those criteria according to which RCT performs well, then, are precisely those that reinforce an Enlightenment self-image of “man” as a rational autonomous actorand which seek to keep hidden the realities of our actual bodies, emotions, and interdependences.

\section{But Could RCT be “Expanded”?}

Sometimes adherents of RCT --while admitting that perhaps RCT has glossed over some important issues in the past-will object to the idea that RCT is a sterile approach. They see the remedy to past failings as not less RCT but more. By tweaking an assumption here or there, other aspects of human nature and behavior can be brought into the RCT fold, they claim. Generally, however, this leads only to somewhat more sophisticated versions of the sorts of absurdity previously discussed.

For example, while RCT has traditionally focused on people's rationality (from the left side of Table 1), the topic of emotion (from the right side of Table 1) has recently become fashionable among a subgroup of mainstream economists. This could potentially develop into a movement towards increased realism and usefulness, since we are, in fact, emotional as well as reasonable creatures. Economists who take emotion seriously might,

${ }^{7}$ The bias towards separative/soluble notions is highly apparent in those philosophical and social theories whose central character ("human" or "citizen") is a "head of household" (thus subsuming everyone else in the household under the "head's" rationality). The bias toward separative notions is also apparent in other RCT-related fields, such as when maximization-based computer simulations of evolutionary processes treat only a single entity, ignoring co-evolutionary dynamics. 
for example, start to notice how advertisers play on our emotions in order to keep us perpetually dissatisfied and always aspiring to make ourselves happier through our purchases. We might notice that many jobs - and especially the particularly "caring” sorts of jobs traditionally held by women--have important emotional as well as instrumental components. This might cause us to rethink and enrich our basic assumptions about what motivates people to work. Taking emotions seriously could have important ramifications for the study of inequality, for macroeconomics (in encouraging more study of Keynes' “animal spirits”) and in many other fields of economics. Some economists, including George Akerlof, Colin Camerer, Robert Frank, Bruno Frey, Jonathan Gruber, Alan Krueger, and Robert J. Shiller, drawing on work by the likes of Richard Easterlin and Daniel Kahneman, have begun to explore the empirical implications of a richer psychological model of human behavior. ${ }^{8}$ This could lead to a very useful re-thinking of core economic assumptions, epistemological values, and methodological habits, resulting in fruitful empirical work and helpful gains in knowledge.

Or it may not. I believe that the ultimate usefulness of this research will depend crucially on how willing my discipline is to let go of its one-sided worship of the ideals valorized in RCT.

For one thing, a large number of RCT economists will resist any introduction of real psychology into economics. Some observers, for example, have expressed fears that "behavioral findings might actually undermine the general unified theory that makes economics unique among the social sciences” (Kopcke, Little, and Tootell, 2004, 4). It remains to be seen how much headway behavioral realists will be able to make against RCT idealists.

Among scholars who have begun to discuss the topic of emotion, there remains a tendency to incorporate it in RCT only as a secondary consideration or "tweak" to the model, while the core ideal of rationality is kept firmly in place. At a session at the most recent American Economics Association meetings, for example, neuroscientist Jonathan Cohen (2005) spoke about how emotions cause us to make "mistakes" in our otherwise (presumably) rational (that is, optimizing and consistent) judgments. Jon Elster (1998, 1999) has likewise treated "rational decision making undisturbed by arousal" as "the paradigm of free, voluntary choice” $(1999,4)$. Rejecting what is now considerable evidence from neuroscientific studies (e.g. Damasio, 1994; Edelman and Tononi, 2000), Elster has denied that emotions could play any valuable role in cognition and action (1999, 158).

Even when emotions are given a little more serious consideration--and a little more credit for keeping us alive and engaged with one another-there is still the danger that RCT epistemological and methodological strictures will be imposed. That is, while

\footnotetext{
${ }^{8}$ See, for examples, programs of the conferences "How Humans Behave” sponsored by the Federal Reserve Bank of Boston (Kopcke, Little, and Tootell, 2004) and "Why Inequality Matters: Lessons for Policy from the Economics of Happiness" sponsored by the Brookings Institution (http://www.brookings.edu/comm/events/20030605.htm)
} 
one of the core assumptions about human behavior may be loosened, the belief that economic knowledge is gained through specifying mathematical maximization problems may be retained. Let me elaborate on one specific example to demonstrate this danger. George Lowenstein and Ted O'Donoghue (2004) have created a model in which the agent maximizes a function that is a linear combination of single-valued outcomes arising from two systems. The "deliberative" system corresponds to the usual rational choice problem, while the "affective" system reflects emotional input. The model has a certain plausibility in explaining situations where emotional impulse seems to dominate rational reflection. But Lowenstein and O’Donoghue's model has only plausibility. Nothing I have read in actual cognitive science would indicate that the analytical and emotional systems are as separate as they appear in this model, that they each yield up a singlevalued result, or that aggregating the two results in a linear equation is the right way of describing how they translate into action. I consider the functional representation chosen by Lowenstein and O'Donoghue to be no more than a heuristic device for presenting the topic to economists who are too rigid to understand human behavior in any other way. While the literature review in this paper is interesting, the authors' formalization adds nothing of actual interest or validity. The linear combination they posit is plausible in exactly the same way that people in the past found it plausible that the sun rose and set over a flat earth. Nobel Laureate George Akerlof is another economist who always includes in his work a formal model carefully constructed to cater to the biases and limited understanding of an RCT economist audience. Yet, no doubt, some will praise such formal models for their presumed "rigor" and "elegance" and see them as further proof that RCT can provide a truly general explanation of the world.

Policy results of RCT-with-emotion can be just as absurd as the policy results of pure RCT. Economist Anthony Heyes, for example, has applied a standard mathematical maximization model to the issue of wage levels for nurses (2004). He innovates by allowing for the fact that nurses may feel a "vocation" for their jobs, in contrast to the usual RCT assumption that people have no emotional investment in their job and simply want to minimize work effort. After several pages of equations, he concludes that wages for nurses must be kept low in order to keep the quality of nursing care high. Only by paying a low wage, his model "shows," can a health service be sure it is hiring people who are not in it "just for the money." His model, of course, ignores many countervailing facts. Incorporation of any of these facts would increase realism while drastically qualifying or reversing Heyes' result. ${ }^{9}$ But Heyes' mathematics appear elegant, and his conclusion is right in line with stereotypes that contrast "economic man," to presumably "non-economic" woman, and so the article passed peer review. One can only hope that policymakers do not see this article.

So not only has RCT not advanced economics in good and useful ways in the

\footnotetext{
${ }^{9}$ People can work out of both self-interested and other-interested motivations. Even good nurses have economic needs in regard to mortgages and grocery bills. Nursing teachers and managers can be skilled in noticing who is doing a good job and who is not. Generally high-functioning people usually have good alternatives to any particular job, while people who are low-functioning and have few alternatives are especially likely to remain in low-paying jobs. People who feel well-paid tend to have higher morale, and people with higher morale tend to perform better. For elaboration of this contrasting view, see Nelson (1999) and Folbre and Nelson (2000).
} 
past, I see only more trouble ahead when I think about expanding economics by simply tweaking RCT's assumptions. When realism and usefulness are not among the ideals respected within a group of theorists, one can hardly expect realistic and useful results to follow.

\section{Why RCT is Bad Science}

The model of "science” on which RCT assumptions are based is geometry, as we saw in Mill's initial conceptualization. The mathematical working out of optimization models in economics was explicitly modeled on late 17th-century Newtonian mechanical physics. The macho culture of RCT dictates that whatever does not follow its strictures should be considered "soft" and inferior.

Real science, however, doesn't stay with a model for 300 hundred years just because it feels "tough.” Real science is characterized by exploration and openness to alternatives. Real investigators do not settle for mere plausibility in their theories, but compare theories to each other and to the evidence. Real physics, in fact, has moved far beyond its original search for "natural law.” In twentieth century physics, the development of quantum theory, the theory of relativity, and most recently the study of chaos and complexity reveals that the universe has non-mechanical, unpredictable, nonlinear, seemingly incommensurable, and surprising behaviors. Quite turning the idea that social sciences (or humanities) should emulate the "hard sciences" on its head, physicists Nigel Goldenfeld and Leo P. Kadanoff wrote in an introduction to a section of Science entitled "Beyond Reductionism,"

Up to now, physicists looked for fundamental laws true for all times and all places. But each complex system is different; apparently there are not general laws for complexity. Instead, one must reach for 'lessons' that might, with insight and understanding, be learned in one system and applied to another. Maybe physics studies will become more like human experience.

$(1999,89)$

Real, open-minded investigators are not so afraid to be messy.

What is the status of RCT, considered as an attempt at science? Is it really a "theory"? People actually engaged in scientific endeavor use both the creation of hypotheses and empirical investigation to try to gain knowledge. Hypotheses--unproven conjectures or propositions--are compared to empirical evidence and to alternative explanations. Generally, only a hypothesis that has been verified to some degree by empirical testing deserves the label of "theory." In this sense RCT is a misnomer, given that the preponderance of empirical evidence stacks up against it.

It might be better, then, to call it RCH for "Rational Choice Hypothesis." Occasionally hypotheses that are manifestly false can still play a useful role in structuring our thinking, by playing the role of a counterfactual. It is in this sense that I think one might arguably grant that RCH could have a very limited role as one among many tools 
of analysis. Temporarily entertaining the possibility that RCH might be true in a particular case may highlight certain aspects of a problem and help sharpen our thinking about alternative and more adequate explanations. RCH could, in this way, arguably be one tool in a expansive toolbox, in the humanities as well as economics. It could be considered to be a set of propositions occasionally useful in a thought-experiment sense, though recognized as generally inadequate on its own as explanation of actual behavior. This sort of open-minded entertainment of RCH would be consistent with a knowledgemaking endeavor that is devoted to coming up with well-founded theories about realworld phenomena.

I hesitate, however, in voicing even such a limited endorsement of $\mathrm{RCH}$, since I am doubtful about the willingness of RCH enthusiasts to carry through and seriously investigate alternative theories. As Theda Skocpol has put it, RC theorists generally have a habit of engaging in a "studied ignorance about their chief theoretical competitors" (2000, 675).

So what of the claim that the propositions of rational choice should enjoy "explanatory privilege" in spite of the dramatic lack of verification they have received from empirical evidence? While suggested by some people for the humanities, and certainly firmly believed by many economists, this is quite odd. It goes against all notions from science about appropriate procedures for adequate knowledge-making. The belief that the proposition of rational choice should be granted an honored status, before and in spite of consideration of the evidence, cannot be called RCT nor RCH. It is RCDRational Choice Dogma. It's immunity to evidence shows that its nature is that of a belief system or religion, not of an investigatory practice.

\section{RCD for the Humanities?}

The point of this quick tour through the history of economics and the philosophy of science has been to point out that, while characteristics such as precision and elegance are good things, pursued on their own they are dangerous. Therefore any assertion that RCD should be "privileged" on account of its precision and elegance should be recognized for what it is: a revelation of the speaker's a priori, knowledge-squelching, biases.

But, I expect, when evaluating the application of RCD to topics in the humanities, one might want to make more specific critiques. These can be elaborated by noting that many of the concepts that RCD makes as thin as possible are those very issues in human life that good literature, philosophy, and history seek to investigate in all their richness and complexity. Good psychology improves on RCD by seeking to understand the actual embodied and embedded processes that underlie human behavior in real time. Good practice in the humanities, to my mind, goes even one better than that, raising the questions of what all these processes are about, or for, and who it is that does them.

RCD forecloses discussion of issues of human identity by starting with the premise that the world is made up of autonomous individuals, defined as the locus of 
decision-making activity. The humanities should be actively investigating questions like "What is a person, in relation to time, space, society, and the rest of nature?"

RCD forecloses discussion of real history and real novelty by staying largely within a static and deterministic framework. The humanities should be actively investigating questions like "How are the truly novel situations that arise in evolving human life, and in the larger histories of societies and nations, playing out?"

A key assumption in RCD is that all things are commensurable. That is, all alternatives facing a person are assumed to be of a nature similar enough to each other that they can be summarized by a single-valued function. In economics you see this when it is assumed, for example, that a single utility function can reflect a person's preferences among activities as diverse as eating ice cream, having children, committing a crime, or saving for the future. Elster has provided a good example of this when he seeks to show that "the process of artistic creation is guided by the aim of maximizing aesthetic value under constraints” (2000, 200, emphasis in original). Complete with graphs and (labored) analogies to calculus (in the form of marginal analysis), his exposition takes it for granted that "aesthetic value" is quantitative and single-valued. There is no room in this set up for valuing, for example, one work of art for its line, another for its color, another for its texture, another for the inarticulate emotions it stirs in your soul. RCD cannot allow qualitative difference, only quantitative. To achieve precision, it must point to a result and a decision. Even though Elster allows that artists (unlike economists and philosophers?) might value "fullness" as well as parsimony, the underlying assumption is that success in reaching each of these goals can each be unambiguously measured in numerical form, and then the resulting numbers can be unproblematically aggregated into a single number reflecting "aesthetic value.” Such a reductionistic approach, I believe, does more than just offend against what we know from psychology about human behavior. It offends against the most basic notions of what art is about. Rather than assuming commensurability, human inquirers must be free to ask questions such as "What is valuable? How do people deal with conflicts between their values? What are the real problems and dilemmas of life, and how do we live and make meaning in their midst?" The humanities seem to me to be especially appropriate venues for such discussions.

At the time of the Enlightenment, one of the big questions was "How is man [sic] different from the animals?" The answer given was "man [sic] alone possesses reason.” Now, after advances in physics and computer science, we have come to simulate with computational machinery a good deal of the quantitative and logical reasoning we previously had thought of as our unique human birthright. The more interesting question, now, for many philosophers and cognitive scientists, has become "How are humans different from computers?" The answer offered by many is "humans have human bodies.” We are, and always have been, animals ourselves. After centuries of fascination with logic and quantification, the leading edge of science is now in biology, with the issues of "qualia" and "valence," or how our mind senses qualities and makes emotional valuations, coming to the fore (Edelman and Tononi, 2000). 
RCD may be "sold" to the humanities as "hard" and "scientific," but it reflects an image of scientificity grounded in the worldview of the 17th century. Humanities would be better to meet contemporary real sciences on the ground of exploring complex, valueladen and incommensurable human experience.

The best economists know this, too. One of the most promising developments in contemporary economics, for example, is economist and philosopher Amartya Sen's (1985) “capability approach,” which evaluates institutions, policies, and actions in terms of the opportunities they give people for valuable ways of living. Sen refuses to limit his list of noteworthy capabilities or propose a method of aggregation that would allow his list to be reduced to a simple problem of single-valued maximization. In insisting on dealing with issues of value and incommensurability head on, Sen's work could be described as a useful importation of a more humanities-oriented sensibility into economics.

\section{Conclusion}

Rational Choice Theory (RCT) is a misnomer, since evidence is hugely against the Rational Choice Hypothesis (RCH) as explanatory of human behavior. The argument for the primacy of a particular, peculiar, and highly gendered subset of ideals reflects Rational Choice Dogma (RCD), a dangerous species of belief system. RCD sacrifices truth and usefulness on the altar of precision and elegance. It leads to a confusion of narrowness and formalism with advances in knowledge.

John Stuart Mill was the originator of the image of humans as rational, selfinterested individuals, and of the image of economic theorizing as a deductive enterprise. But he rightly warned that any application of this narrow model without reference to other disciplines or to experience could lead to absurdity. He also was an often perceptive observer of human behavior:

But such is the nature of the human understanding, that the very fact of attending with intensity to one part of a thing, has a tendency to withdraw the attention from the other parts...And if we are in this predicament, the more accurate our deductions and the more certain our conclusions in the abstract...the less we are likely to suspect that we are in error: for no one can have looked closely into the sources of fallacious thinking without being deeply conscious that the coherence, and neat concatenation of our philosophical systems, is more apt than we are commonly aware to pass with us as evidence of their truth. (Mill, 1844, 63-64)

I, for one, will vote for truth over neatness.

Julie A. Nelson is a Senior Research Associate at the Global Development and Environment Institute at Tufts University, USA. Inquiries can be directed to Julie.Nelson@tufts.edu. 


\section{REFERENCES}

Barsky, Robert B. and Lutz Kilian. 2004. Oil and the macroeconomy since the 1970s. The Journal of Economic Perspectives 18(4): 115-134.

Blaug, Mark. 2002. Endogenous growth theory,” in Brian Snowdon and Howard R. Vane, eds, An Encyclopedia of Macroeconomics, Cheltenham: Edward Elgar, pp. 202-212.

Bordo, Susan. 1986. “The Cartesian Masculinization of Thought.” Signs: Journal of Women in Culture and Society 11(3): 439-456.

Cohen, Jonathan. 2005. The vulcanization of the human brain: The neural bases of cognition-emotion interactions in decision. Paper presented at the American Economic Association meetings, Philadelphia, Jan. 7.

Damasio, Antonio R. (1994) Descartes' Error: Emotion, Reason, and the Human Brain. (New York, G.P. Putnam's Sons)

Edelman, Gerald and Tononi Giulio. 2000. A Universe of Consciousness. NY: Basic.

Davis, Philip J. and Reuben Hersh. 1987. Rhetoric and mathematics, in John S. Nelson et al., eds., The Rhetoric of the Human Sciences, 53-68. Madison: University of Wisconsin Press.

Elster, Jon. 1990. When rationality fails, in Karen Schweers Cook and Margaret Levi, eds, The Limits of Rationality. Chicago: The University of Chicago Press. . 1998. Emotions and economic Theory, Journal of Economic Literature 36: 47-74. . 1999. Strong Feelings: Emotion, Addiction, and Human Behavior. Cambridge:

MIT Press. . 2000a. Ulysses Unbound. Cambridge: Cambridge University Press.

Elster. 2000b. Rational choice history: A Case of excessive ambition. American Political Science Review 94(3): 685-695.

England, Paula (2003) Separative and soluble Selves: Dichotomous thinking in economics, in M. A. Ferber and J. A. Nelson (Eds) Feminist Economics Today: Beyond Economic Man, pp. 33-59 (Chicago, University of Chicago Press)

Fee, Elizabeth. 1983. Women's nature and scientific objectivity, in Marian Lowe and Ruth Hubbard, eds., Women's Nature: Rationalizations of Inequality, 9-27. New York: Pergamon Press.

Ferriera, M. Luisa, Reuben C. Buse, and Jan-Paul Chavas. 1998. Is there bias in the economic literature on equivalence scales? Review of Income and Wealth 44(2): 183-198.

Folbre, Nancy and Julie A. Nelson. 2000. For love or money--Or both? Journal of Economic Perspectives 14(4), 123-140.

Georgescu-Roegen, Nicholas. 1971. The Entropy Law and the Economic Process. Cambridge: Harvard University Press.

Goldenfeld, Nigel and Leo P. Kadanoff. 1999. Simple lessons from complexity. Science, Vol. 284, April 2, 87-89.

Harding, Sandra. 1986. The Science Question in Feminism. Ithaca: Cornell University Press.

Heyes, Anthony. 2004. The economics of vocation or 'why is a badly paid nurse a good nurse'? Journal of Health Economics online, http://www.sciencedirect.com/science/journal/01676296, accessed 3/10/05. 
Kahneman, Daniel. 2003. Maps of bounded rationality: psychology for behavioral economics. The American Economic Review 93(5), 1449 -1475.

Keller, Catherine. 1986. From A Broken Web: Separation, Sexism, and Self. Boston: Beacon Press.

Keller, Evelyn Fox. 1985. Reflection on Gender and Science. New Haven, Conn: Yale University Press.

Kopcke, Richard W., Jane Sneddon Little and Goeffrey M.B. Tootell. 2004. How humans behave: Implications for economics and economic policy. New England Economic Review, First Quarter, 4-35. http://www.bos.frb.org/economic/neer/neer2004/neer04a.pdf

Loewenstein, George and Ted O’Donoghue. 2004. Animal spirits: Affective and deliberative processes in economic behavior. Working paper. http://gsbwww.uchicago.edu/research/workshops/behavioral/lowenstein.pdf accessed 3/11/05.

Lucas, Robert E., Jr. 1987. Models of Business Cycles. Oxford: Basil Blackwell.

Mill, John Stuart, 1844. Essay V: On the definition of political economy; and on the method of investigation proper to it, in Essays on Some Unsettled Questions of Political Economy. London: Longmans, Green, Reader, and Dyer Co., 1874. Second edition. http://www.econlib.org/library/Mill/mlUQP5.html.

Nelson, Julie A. 1996. Feminism, Objectivity and Economics. London: Routledge. . 1999. Of markets and martyrs: Is it ok to pay well for care?" Feminist Economics 5(3), 43-59. . 2001. Feminist economics: Objective, activist and postmodern? in Stephen Cullenberg, Jack Amariglio and David F. Ruccio (eds) Postmodernism, Economics and Knowledge. London: Routledge.

Persky, Joseph. 1995. The ethology of homo economicus, Journal of Economic Perspectives, 9 (2), Spring, 221-231.

Skocpol, Theda. 2000. Commentary: Theory tackles history. Social Science History 24(4): 669-676.

Sen, Amartya. .1985. Commodities and Capabilities. Amsterdam, North-Holland.

Simon, Herbert A. 1955. A behavioral model of rational choice, Quarterly Journal of Economics 69(1), 99-118. 
The Global Development And Environment Institute (GDAE) is a research institute at Tufts University dedicated to promoting a better understanding of how societies can pursue their economic goals in an environmentally and socially sustainable manner. GDAE pursues its mission through original research, policy work, publication projects, curriculum development, conferences, and other activities. The "GDAE Working Papers" series presents substantive work-in-progress by GDAE-affiliated researchers. We welcome your comments, either by e-mail directly to the author or to G-DAE, Tufts University, 44 Teele Ave., Medford, MA 02155 USA; tel: 617-627-3530; fax: 617-627-2409; e-mail: gdae@tufts.edu; website: http://ase.tufts.edu/gdae.

\section{Papers in this Series:}

00-01 Still Dead After All These Years: Interpreting the Failure of General Equilibrium Theory (Frank Ackerman, November 1999)

00-02 Economics in Context: The Need for a New Textbook (Neva R. Goodwin, Oleg I. Ananyin, Frank Ackerman and Thomas E. Weisskopf, February 1997)

00-03 Trade Liberalization and Pollution Intensive Industries in Developing Countries: A Partial Equilibrium Approach (Kevin Gallagher and Frank Ackerman, January 2000)

00-04 Basic Principles of Sustainable Development (Jonathan M. Harris, June 2000)

00-05 Getting the Prices Wrong: The Limits of Market-Based Environmental Policy (Frank Ackerman and Kevin Gallagher, September 2000)

00-06 Telling Other Stories: Heterodox Critiques of Neoclassical Micro Principles Texts (Steve Cohn, August 2000)

00-07 Trade Liberalization and Industrial Pollution in Mexico: Lessons for the FTAA (Kevin Gallagher, October 2000) (Paper withdrawn- see www.ase.tufts.edu/gdae/ for details)

00-08 Waste in the Inner City: Asset or Assault? (Frank Ackerman and Sumreen Mirza, June 2000)

01-01 Civil Economy and Civilized Economics: Essentials for Sustainable Development (Neva Goodwin, January 2001)

01-02 Mixed Signals: Market Incentives, Recycling and the Price Spike of 1995. (Frank Ackerman and Kevin Gallagher, January 2001)

01-03 Community Control in a Global Economy: Lessons from Mexico’s Economic Integration Process (Tim Wise and Eliza Waters, February 2001)

01-04 Agriculture in a Global Perspective (Jonathan M. Harris, March 2001)

01-05 Better Principles: New Approaches to Teaching Introductory Economics (Neva R. Goodwin and Jonathan M. Harris, March 2001)

01-06 The \$6.1 Million Question (Frank Ackerman and Lisa Heinzerling, April 2002)

01-07 Dirt is in the Eye of the Beholder: The World Bank Air Pollution Intensities for Mexico (Francisco Aguayo, Kevin P. Gallagher, and Ana Citlalic González, July 2001)

01-08 Is NACEC a Model Trade and Environment Institution? Lessons from Mexican Industry (Kevin P. Gallagher, October 2001) 
01-09 Macroeconomic Policy and Sustainability (Jonathan M. Harris, July 2001)

02-01 Economic Analysis in Environmental Reviews of Trade Agreements: Assessing the North American Experience. (Kevin Gallagher, Frank Ackerman, Luke Ney, April 2002)

03-01 Read My Lips: More New Tax Cuts-The Distributional Impacts of Repealing Dividend Taxation (Brian Roach, February 2003)

03-02 Macroeconomics for the $21^{\text {st }}$ Century (Neva R. Goodwin, February 2003)

03-03 Reconciling Growth and the Environment (Jonathan M. Harris and Neva R. Goodwin, March 2003)

03-04 Current Economic Conditions in Myanmar and Options for Sustainable Growth (David Dapice, May 2003)

03-05 Economic Reform, Energy, and Development: The Case of Mexican Manufacturing (Francisco Aguayo and Kevin P. Gallagher, July 2003)

03-06 Free Trade, Corn, and the Environment: Environmental Impacts of US-Mexico Corn Trade Under NAFTA

03-07 Five Kinds of Capital: Useful Concepts for Sustainable Development (Neva R. Goodwin, September 2003)

03-08 International Trade and Air Pollution: The Economic Costs of Air Emissions from Waterborne Commerce Vessels in the United States (Kevin P. Gallagher and Robin Taylor, September 2003)

03-09 Costs of Preventable Childhood Illness: The Price We Pay for Pollution (Rachel Massey and Frank Ackerman, September 2003)

03-10 Progressive and Regressive Taxation in the United States: Who's Really Paying (and Not Paying) their Fair Share? (Brian Roach, October 2003)

03-11 Clocks, Creation, and Clarity: Insights on Ethics and Economics from a Feminist Perspective (Julie A. Nelson, October 2003)

04-01 Beyond Small-Is-Beautiful: A Buddhist and Feminist Analysis of Ethics and Business (Julie A. Nelson, January 2004)

04-02 The Paradox of Agricultural Subsidies: Measurement Issues, Agricultural Dumping, and Policy Reform (Timothy A. Wise, February 2004)

04-03 Is Economics a Natural Science? (Julie Nelson, March 2004)

05-02 Understanding the Farm Problem: Six Common Errors in Presenting Farm Statistics (Timothy A. Wise, March 2005)

05-03 Securing Social Security: Sensitivity to Economic Assumptions and Analysis of Policy Options (Brian Roach and Frank Ackerman, May 2005)

05-04 Rationality and Humanity: A View from Feminist Economics (Julie A. Nelson, May 2005) 